\title{
Paving the Way
}

On the road of progress, where did the asphalt come from?

Throughout history, the creation and maintenance of roads has been a barometer for the rise and fall of civilizations. While other new science and technology developed over the centuries, surprisingly little progress was made in the construction of roads or the materials and techniques used to surface them.

The word "highway" is derived from the Roman roads built on a mound of dirt piled up from ditches on either side, raising the route above the surrounding ground and making it a "high way." The term "road" comes from the Anglo-Saxon rad ("to ride"), for the path on which travelers rode.

The earliest roads developed from paths worn into the ground by travelers. Actual road building did not develop until local governments were powerful enough to take on such projects. The first civilizations to build simple roads probably appeared in southwestern Asia. The Mesopotamians undertook an extensive project to develop a travel route from the Babylonian Empire to Egypt. The Egyptians later adapted these road building skills to provide a solid track for hauling gigantic limestone blocks for the pyramids.

In the seventh and sixth centuries B.C. processional roads connected the cities of Assur, Babylon, and Tall as-Asmar. These roads were paved with burnt brick and stone laid into bituminous mortar; paved city streets were often elaborately decorated with colored tile, bricks, or stones.

In India, archaeological excavations have shown that the Indians used similar materials and techniques (burnt bricks cemented with bitumen) much earlier, as far back as 3250-2750 B.C. By A.D. 75, the Indians also used brick pavement, stone slab pavement, and primitive concrete (both as a foundation or as the road surface). The Indians filled crevices in the road with lime, gypsum, or a bituminous mortar.

Many roads in ancient China were well built and surfaced with stone; however, after the original construction, these roads were not maintained. In fact, a popular saying remarked that a Chinese road was good for seven years and then bad for 4000 years!

The Romans, master roadbuilders, made systematic highways that were remarkably straight, with solid foundations and cambered surfaces. Some of the best road surfaces were slabs of stone laid upon a strong foundation of rubble or broken stone. Other Roman roads used a concrete made from lime and pozzolana (volcanic ash).

For centuries after the downfall of the Roman Empire (about the fifth century A.D.)

\section{The United States and Europe have nearly $5,000,000$ total miles of paved roads-most of which are paved with the same substance used by the Babylonian king Nabopolassar in 3800 B.C.}

these roads degenerated with no central authority to maintain them. Dirt paths became rough and uneven, dusty or muddy depending on the weather. Most traffic consisted of people traveling on foot or on horseback and farmers moving livestock. Merchandise was carried on pack trains. In about 1600, though, the wheeled coach began to see popular use for intercity travel, and the heavy iron tires caused great damage to road surfaces. This forced the development of improved paving materials.

At first these improved roads were surfaced with new stone. Stone-paved toll roads appeared in Britain, across Europe, and even in the American Colonies. In many cities cobblestones were used until the middle of the nineteenth century.

Maintaining a good road surface depends primarily on the type of pavement, the compaction of the underlying material, and the drainage of the surface. Drainage depends on the engineering of the road itself. Techniques for compacting the underlying material improved as roadbuilders began to bring in many shallow layers of material. Historically, sheep were driven over fresh layers to compact the soil. Later, workers used a "sheepsfoot roller" with small steel protrusions like sheeps' feet over the new road surface.

A pavement must transmit the load of a passing vehicle to the underlying soil without damaging the road surface. Paving material must resist the degradation caused by traffic and must also provide a smooth surface for a comfortable ride. Ideally, paving material should resist damage caused by changes in temperature, moisture, and long-term environmental chemical action.

In the 1770 s two self-taught engineers changed roadbuilding methods and materials used throughout Europe-John Loudon McAdam and Pierre Tresauguet. Tresauguet became inspector general of bridges and roads for France in 1775 . He proposed a new theory for a light road surface, suggesting that the subsoil should support the load of traffic, not the surface itself.

McAdam devised an inexpensive, selfsealing pavement of crushed stone, called a "macadam surface," applied directly to the subsoil of a roadbed. McAdam began his work at Bristol, then the second most important city in Britain. In 1816, when McAdam was chosen the general surveyor of the area, the roads were in poor condition. He decided that roadbuilding should be conducted in keeping with fundamental scientific principles, and he experimented with local roads to see how they withstood traffic and time. Like Tresauguet, he believed that the roads should be well drained, with a compacted subsoil to carry most of the load. His philosophy was that the pavement should act only to shed water and to cover the subsoil.

The macadam road consisted of two or more layers of crushed stone compacted with a heavy roller and then bonded together with a fine stone powder pressed into the surface. The stone powder and the crushed stone made for a sturdy surface...adding water to the compaction process made the surface even stronger. The method was so effective that it was widely copied, and macadam roads spread throughout the western world.

McAdam had also recommended binding the stone powder and crushed rock together with slag or a bituminous mixture. Bitumen, or natural asphalt, paving was first laid in Paris in 1854, using rock asphalt from Switzerland.

Asphalt is a material that had been used in building and paving since ancient times (in fact, archaeologists have established that it is one of the oldest adhesives known to man). Early Buddhist writings call asphalt "earth butter." The Mesopotamians 
used it as a mortar for building stones and paving blocks as early as 3800 B.C.

Asphalt is a black or dark brown cementitious material that gradually liquefies when it is heated. Asphalts are complex mixtures of high-molecular-weight hydrocarbons, which can be separated into resins, oils, and asphaltenes (brown to black semicrystalline solids that are hard and brittle).

Natural asphalt, such as that used by the ancients, was occasionally found in seeps and pools, a natural residue of petroleum deposits from geologic processes. Typical pools are the La Brea tar pits in Los Angeles, California, or Pitch Lake on the island of Trinidad, where Columbus stopped to caulk his ships on the way home to Spain. Pitch Lake and Bermudez Lake in Venezuela furnished most of the asphalt used for paving in the United States up until the 20th Century.

The exploitation of these two major sources of natural asphalt stimulated interest in using the material for street paving. When asphalt (and oil or tar) was first used for paving roads in the late nineteenth cen- tury, the primary purpose was to control dust. The mixture could be sprayed on roads as a diluted emulsion. Asphalts could also be used as a binder to fill voids in a macadam base.

Asphalt paving is smooth and easily cleaned, which made it ideal for city streets. The first U.S. stretch of asphalt road was laid in 1870 in front of the city hall in Newark, New Jersey. Now; about $90 \%$ of U.S. city streets are paved with asphalt.

While most secondary roads in the United States are now paved with asphalt, country roads for a long time remained virtually impassible in wet weather...until roadbuilding interest was stimulated again with the advent of bicycle use. Bicycle riding required a somewhat better road surface than horseback riding. Later, the automobile demanded even better roads.

At the beginning of the motor age, petroleum refineries began making a host of byproducts, one of which was asphalt. After 1900, large-scale production of asphalt was accomplished through refining crude petroleum...most crude petroleum contains some asphalt, up to $50 \%$. Early simple refin- ing methods used high-temperature atmospheric distillation. Today, modern fractional-distillation methods have greatly increased the efficiency of asphalt production.

By 1915 heavy automobile traffic showed that asphalt paving could withstand the scuffing and abuse caused by the high speed and heavy weight of automobiles and cargo trucks. The heavy truck traffic of World War I demanded extremely durable pavement, such as asphalt or concrete (which had been used in Britain and Europe since the nineteenth century).

Highway surfacing materials have been developed and tested in the decades since World War I, with little major improvement. The United States and Europe have nearly 5,000,000 total miles of paved roads-most of which are paved with the same substance used by the Babylonian king Nabopolassar in 3800 B.C. He claimed that he had found his realm in mud and had left it "laced with roads glistening with asphalt."

KEVIN J. ANDERSON

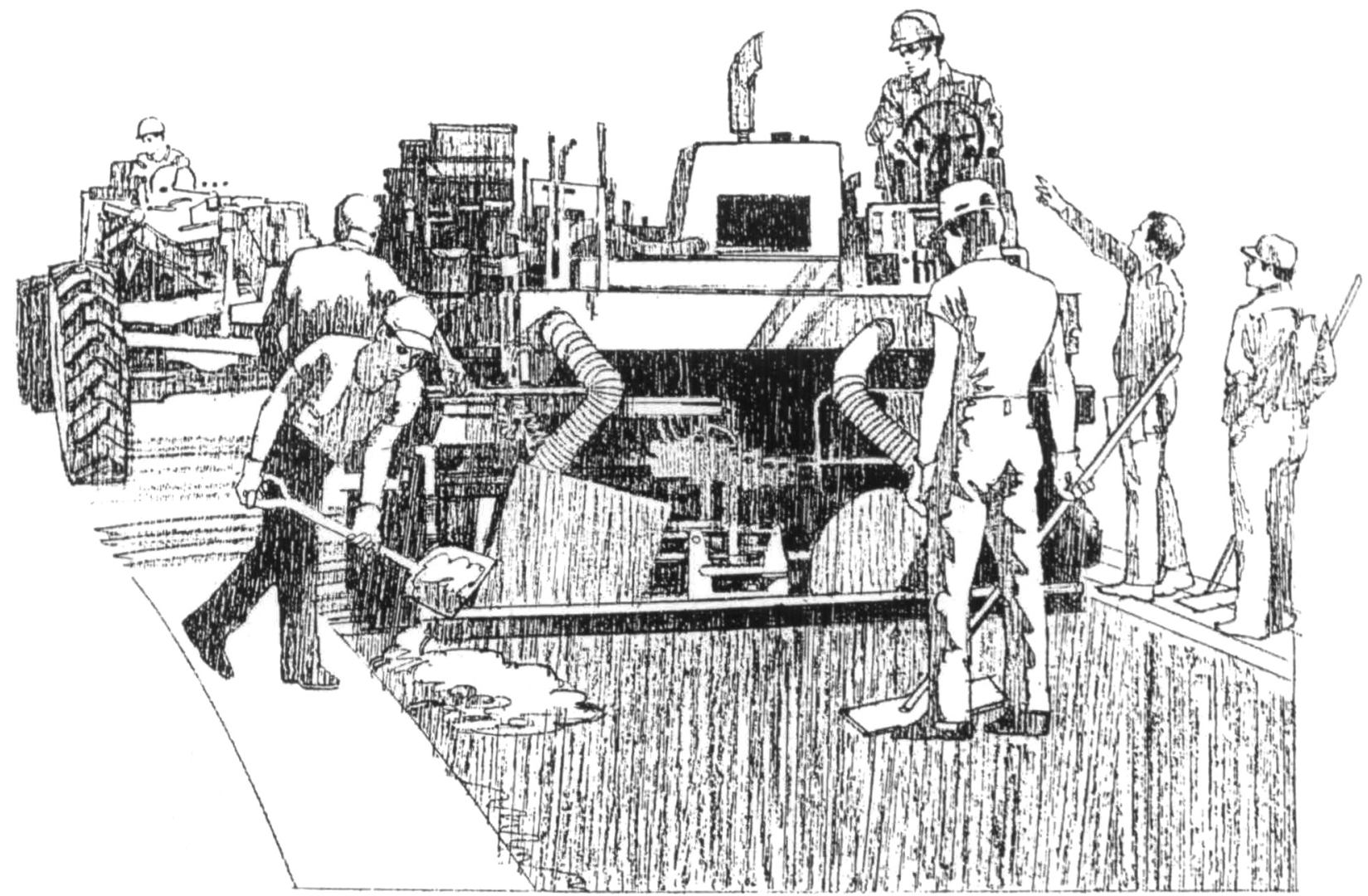

Asphalt paving is smooth and easily cleaned, which makes it ideal for city streets. The first U.S. stretch of asphalt rond was laid in 1870 in front of the city hall in Newark, New Jersey. Now, about $90 \%$ of U.S. city streets are paved with asphalt. 